\title{
Screening of Maize Inbred Lines and Popularly Grown Hybrids against Banded Leaf and Sheath Blight Disease Incited by Rhizoctonia solani f. sp. sasakii Exner
}

\author{
G. Bindu Madhavi ${ }^{*}$, L.N. Hanuman ${ }^{1}$, G. Uma Devi², K. Vijay Krishna Kumar ${ }^{3}$, \\ T. Ramesh Babu ${ }^{4}$ and T.C.M. Naidu ${ }^{5}$ \\ ${ }^{I}$ Department of Plant Pathology, RARS, Lam, India \\ ${ }^{2}$ Department of Plant Pathology, College of Agriculture, PJTSAU, Hyd, India \\ ${ }^{3}$ Department of Agriculture, ANGRAU, India \\ ${ }^{4}$ RARS, Tirupathi, India \\ ${ }^{5}$ Regional Agricultural Research Station, Lam, Guntur, ANGRAU, Andhra Pradesh, India \\ *Corresponding author
}

\section{A B S T R A C T}

\begin{tabular}{|l|}
\hline Ke y w o r d s \\
Maize, BLSB, \\
$\begin{array}{l}\text { Rhizoctonia solani f. sp. } \\
\text { sasakii, Inbred lines, } \\
\text { Hybrid, Disease severity }\end{array}$ \\
\hline Article Info \\
\hline $\begin{array}{l}\text { Accepted: } \\
10 \text { October } 2018 \\
\text { Available Online: } \\
10 \text { November } 2018\end{array}$ \\
\hline
\end{tabular}

Keywords

\section{Introduction}

Maize (Zea mays L.) is the third most important cereal crop after rice and wheat, in the world agricultural economy as food for humans and feed for livestock. About 112 diseases of maize have been reported so far from different parts of the world. Of these, 65 are known to occur in India. The Banded Leaf and Sheath Blight (BLSB) disease, caused by Rhizoctonia solani f. sp. sasakii Exner (teleomorph) Thanatephorus sasakii Shirai, is

\begin{abstract}
Banded Leaf and Sheath Blight (BLSB) disease caused by Rhizoctonia solani f. sp. sasakii Exner was studied in 22 inbred lines and 12 hybrids at the Regional Agricultural Research Station farm, Lam, Guntur, during rabi 2014-15 for evaluating resistance. Out of 22 inbred lines, PFSR9-2 had shown resistant reaction whereas PFSR6-1, PFSR6-2 and PFSR18 were found to be moderately resistant to BLSB disease. In case of hybrids, DHM 117 is the only hybrid which had shown resistant reaction, DKC9145, DKC9133 and KMH3110 were found moderately resistant and the remaining have shown susceptible reaction. The laboratory and field evaluation data corresponded in actual disease rating as well as in terms of categorization in to resistant, moderately resistant, susceptible and highly susceptible.
\end{abstract}

considered as one of the most important diseases of maize in South- and South-East Asia (Sharma and Saxena, 2002), and has potential ability to cause significant yield reduction and loss in fodder quality (Sharma et al., 2000).

In India, the disease is more prevalent during kharif season and favours temperature of 25$30^{\circ} \mathrm{C}$ and R.H.100\% (Ahuja and Payak, 1981). In India, the disease is more prevalent during kharif season and favours temperature of $25-$ 
$30^{\circ} \mathrm{C}$ and R.H.100\% (Ahuja and Payak, 1981).

It causes considerable amount (23.9 to $31.9 \%$ or more) of crop yield loss at favourable condition (Lal et al., 1980). Further, it is estimated that $1 \%$ of total grain yield of India is lost by the disease every year (Payak and Sharma, 1985).

With the popularize and extensive planting of compact hybrids, heavy use of nitrogen fertilizer, the increase in planting density in maize production facilitates the rapid spread of BLSB, which caused a decreased production of 10 to $20 \%$ or even higher ((Huang et al., 2007). Different approaches for the management of BLSB have been suggested, including mechanical control through stripping of the two lower leaves along with the leaf sheath (Sharma and Hembram, 1990) and chemical control (Jiang et al., 1991; Sharma and Rai, 1998). The mechanical means of stripping the lower leaves effectively checks the further spread of the disease to the upper leaves and the ear, but the method is labour-intensive, and is also not cost- and time-effective. Similarly, chemical control is expensive and less environment friendly. Therefore, increasing emphasis is currently being laid on host-plant resistance to BLSB hence comprehensive efforts involving a wider range of germ plasm and rigorous evaluation at multiple locations are required. With this background, the present study was undertaken with an objective to analyze the genetic variability in the maize inbred lines and popularly grown hybrids for resistance to BLSB at RARS, Lam, Guntur, Andhra Pradesh

\section{Materials and Methods}

The popularly cultivated maize hybrids and the inbred lines developed by Maize Research Centre, Rajendranagar, PJSTS Agricultural
University in pipeline were screened for their resistance against BLSB under artificial epiphytotic condition during rabi 2014-15 in field and lab conditions. Since the isolate NSP-34 from Narsaraopet mandal of Guntur district was found to be highly virulent in the previous study, hence the same isolate was used for screening hybrids and inbred lines

\section{Screening under lab conditions}

For laboratory testing, the leaves were collected from 30 days old plants in the afternoon for reasons given by Payak (1955). Leaf pieces were cut in to suitable size $(8 \times 5.5 \mathrm{~cm})$, washed in tap water and floated on $8 \mathrm{ml}$ of $2 \mathrm{ppm}$ kinetin solution in petridishes. Five replicates having one leaf piece in each dish were maintained for all entries.

The leaf pieces were inoculated by placing sclerotia on the midrib of adaxial surface and incubated at $28+1{ }^{\circ} \mathrm{C}$ for 7 days. Observations on disease development were recorded after 3 days and number of sclerotia developed was counted after 7 days of inoculation on the basis of the scale given by Ahuja and Payak, 1981.

\section{Rating scale for banded leaf and sheath blight}

Screening under field conditions A total of 22 inbred lines and 12 hybrids of maize were screened against BLSB under artificial epiphytotic conditions in RARS, Lam field. Each inbred line/hybrid was planted in a $5 \mathrm{~m}$ long single row replicated twice in a randomized block design. Inoculation was made on 45 days old plants by toothpick method High humidity (>90\%) was maintained throughout the disease development period by frequent irrigations. Disease assessment was made at 35 days after inoculation using 1-5 scale as described by Ahuja and Payak (1978) 


\section{Rating scale}

Disease is recoded after 30-35 days of inoculations on basis of following rating scale.

Infection is on one leaf sheath, lesions are one or few, non-coalescent

Infection is on two to three leaf sheaths, lesions are few and non-coalescent on third leaf sheath from ground level.

Infection is not up to the ear shoot but on more than two leaf-sheaths

Infection is on all leaf sheaths up to the ear shoot but shank is not infected. Infection presents beyond the ear shoot; reduced ear size, husk leaves bleached and caked with or without sclerotial development; kernel formation absent or rudimentary

Mass multiplication of $R$. solani inoculum: Rice stem pieces (35-40 days old plants) were cut in to pieces of about $2 \mathrm{~cm}$ size and filled in to $2 \mathrm{~kg}$ polypropylene (PP) bags up to one third. Ten $\mathrm{ml}(1 \%)$ peptone + sucrose $(1: 1)$ solution was added in each PP bag and then autoclaved at 15 pascals per square inch (p.s.i_) for 30 minutes. Mycelial discs of $5 \mathrm{~mm}$ diameter of BLSB pathogen cut from the margin of 3- days-old culture of the pathogen were inoculated in to the PP bags and incubated at $26+2{ }^{0} \mathrm{C}$ for fifteen days. Inocula multiplied on rice stem pieces were used for inoculating the maize inbred lines and hybrids for screening.

At least 10 plants in each replication for each entry were scored and the disease scores were used to estimate Disease Index (DI) for each genotype, as suggested by Wang and Dai (2001), as follows: DI $=[\mathrm{L}$ (severity class or disease score $\mathrm{x}$ number of plants in this class) I the highest possible severity class or disease score $\mathrm{x}$ total number of investigated plants] $\mathrm{x}$
100. The responses of the genotypes were rated using the 01 values, based on the following scale: 0-30-resistant; >30- 60moderately resistant; >60-90-susceptible; and $>90-1$ OO-highly susceptible.

\section{Results and Discussion}

The study was designed to identify new sources of resistance to BLSB which can be used in developing resistant cultivars to this disease with a view to mitigate loss in farmer's fields.

The data of screening inbred lines and hybrids under laboratory conditions was presented in Table 1. The fungal growth from sclerotia increased and spread with in $12 \mathrm{hr}$, infection cushions appeared 1-2 $\mathrm{cm}$ away from the inoculums point $18 \mathrm{hr}$ after inoculation. Initially these were hyaline but after $24 \mathrm{hr}$ they turned brown and finally straw coloured spots of 0.5- $0.8 \mathrm{~mm}$ diameter and became apparent. The diameter of the spots increased after $48 \mathrm{hr}$ of incubation. The lesions were surrounded by water soaked greyish areas. The symptoms expressed themselves in the form of small spots to lesions covering most of the leaf lamina. Number of sclerotia produced were ranged from 4- 34 per plate. The inbred line PFSR9-2 and hybrid DHM117 have shown resistant reaction with average disease score 1 but developed on an average 9 and 7 sclerotia per leaf bit in petridish. PFSR6-1, PFSR6-2 and PFSR18 were found to be moderately resistant with disease score 2.4, 2.2 and 2.7 and no. of sclerotia 19,14 and 8 respectively (Plate 1).

The results of evaluation of hybrids and inbred lines against BLSB under field conditions were presented in Table 2 and it was found that there were significant difference among the lines and hybrids on disease incidence, indicated the genetic variability for the trait under study. 
Table.1 Reaction of maize inbred lines and released hybrids to Banded Leaf and Sheath Blight induced by $R$. solani f.sp. sasakii in laboratory

\begin{tabular}{|c|c|c|c|c|c|}
\hline S. No. & Inbred lines/ Hybrid & $\begin{array}{c}\text { Average } \\
\text { Disease grade }\end{array}$ & $\begin{array}{l}\text { Average no. of } \\
\text { sclerotia } \\
\text { produced/leaf bit }\end{array}$ & PDI & $\begin{array}{c}\text { Reaction } \\
\text { type* }\end{array}$ \\
\hline 1. & PFSR-1 & 4.9 & 18 & 97 & HS \\
\hline 2. & PFSR-6-1 & 2.3 & 19 & 45 & MR \\
\hline 3. & PFSR 6-2 & 2.3 & 14 & 46 & MR \\
\hline 4. & PFSR-9-2 & 1.0 & 9 & 20 & $\mathbf{R}$ \\
\hline 5. & PFSR13 & 4.7 & 34 & 94 & HS \\
\hline 6. & PFSR-15 & 4.1 & 9 & 82 & HS \\
\hline 7. & PFSR18 & 2.4 & 8 & 48 & $\mathbf{S}$ \\
\hline 8. & PFSR-25 & 4.3 & 25 & 85 & HS \\
\hline 9. & PFSR-41 & 3.1 & 11 & 62 & $\mathbf{S}$ \\
\hline 10. & PFSR-10 & 4.2 & 24 & 83 & HS \\
\hline 11. & BPT -7 & 3.9 & 7 & 78 & HS \\
\hline 12. & BPT-10 & 4.5 & 15 & 89 & HS \\
\hline 13. & BPT-19 & 4.1 & 6 & 81 & HS \\
\hline 14. & BPT-20 & 3.4 & 15 & 68 & \\
\hline 15. & BPT-22 & 4.4 & 25 & 87 & HS \\
\hline 16. & BPT- 30 & 3.4 & 22 & 68 & $\mathbf{S}$ \\
\hline 17. & TR 5-1 & 3.1 & 12 & 62 & $\mathbf{S}$ \\
\hline 18. & TR-2 & 2.4 & 19 & 48 & $\mathbf{S}$ \\
\hline 19. & TR 30 & 3.1 & 23 & 62 & $\mathbf{S}$ \\
\hline 20. & TR-72 & 2.5 & 27 & 49 & $\mathbf{S}$ \\
\hline 21. & TR-74 & 4.6 & 10 & 91 & HS \\
\hline 22. & TR-83 & 3.1 & 4 & 62 & $\mathbf{S}$ \\
\hline 23. & DHM-117 & 1.0 & 7 & 20 & $\mathbf{R}$ \\
\hline 24. & DHM-121 & 3.0 & 20 & 59 & $\mathbf{S}$ \\
\hline 25. & Pinnacle & 2.4 & 19 & 48 & HS \\
\hline 26. & DKC 9126 & 3.5 & 14 & 69 & HS \\
\hline 27. & DKC 9145 & 2.7 & 10 & 54 & $\mathbf{S}$ \\
\hline 28. & DKC 9133 & 2.4 & 5 & 47 & MR \\
\hline 29. & DKC 8101 & 3.2 & 17 & 63 & $\mathbf{S}$ \\
\hline 30. & KMH super 244 & 3.7 & 11 & 73 & HS \\
\hline 31. & KMH 25K45 & 4.1 & 21 & 82 & HS \\
\hline 32. & KMH 3110 & 2.4 & 8 & 48 & MR \\
\hline 33. & Pioneer 30 V 92 & 4.1 & 10 & 82 & HS \\
\hline \multirow[t]{3}{*}{34.} & Pioneer 3396 & 4.2 & 15 & 83 & HS \\
\hline & Sem & 0.12 & & & \\
\hline & CD & 0.36 & & & \\
\hline
\end{tabular}

1- Resistant (R); 1.1-2.5 Moderately resistant (M R) 2.6-3.5- Susceptible (S), 3.6-5.0 -Highly Susceptible (H S) 
Table.2 Reaction of maize inbred lines and released hybrids to Banded Leaf and Sheath Blight induced by $R$. solani f. sp. sasakii under artificial inoculation conditions in field

\begin{tabular}{|c|c|c|c|c|}
\hline S. No. & $\begin{array}{l}\text { Inbred lines/ } \\
\text { Hybrid }\end{array}$ & $\begin{array}{c}\text { Average Disease } \\
\text { grade }\end{array}$ & PDI & Reaction type* \\
\hline 1. & PFSR-1 & 4.1 & 82 & HS \\
\hline 2. & PFSR-6-1 & 2.4 & 48 & MR \\
\hline 3. & PFSR 6-2 & 2.2 & 44 & MR \\
\hline 4. & PFSR-9-2 & 1.0 & 20 & $\mathbf{R}$ \\
\hline 5. & PFSR13 & 4.6 & 91 & HS \\
\hline 6. & PFSR-15 & 4.6 & 92 & HS \\
\hline 7. & PFSR18 & 2.7 & 54 & $\mathbf{S}$ \\
\hline 8. & PFSR-25 & 4.1 & 82 & HS \\
\hline 9. & PFSR-41 & 3.1 & 61 & $\mathbf{S}$ \\
\hline 10. & PFSR-10 & 4.5 & 89 & HS \\
\hline 11. & BPT -7 & 3.9 & 78 & HS \\
\hline 12. & BPT-10 & 4.2 & 84 & HS \\
\hline 13. & BPT-19 & 4.0 & 80 & HS \\
\hline 14. & BPT-20 & 3.6 & 71 & HS \\
\hline 15. & BPT-22 & 4.1 & 82 & HS \\
\hline 16. & BPT - 30 & 3.8 & 75 & $\mathbf{S}$ \\
\hline 17. & TR 5-1 & 3.0 & 59 & MR \\
\hline 18. & TR-2 & 2.6 & 52 & MR \\
\hline 19. & TR 30 & 3.1 & 62 & $\mathbf{S}$ \\
\hline 20. & TR-72 & 2.9 & 58 & MR \\
\hline 21. & TR-74 & 4.3 & 86 & HS \\
\hline 22. & TR-83 & 2.9 & 58 & $\mathbf{S}$ \\
\hline 23. & DHM-117 & 1.0 & 20 & $\mathbf{R}$ \\
\hline 24. & DHM-121 & 3.1 & 61 & $\mathbf{S}$ \\
\hline 25. & Pinnacle & 4.0 & 80 & MR \\
\hline 26. & DKC 9126 & 3.6 & 72 & MR \\
\hline 27. & DKC 9145 & 2.8 & 55 & $\mathbf{S}$ \\
\hline 28. & DKC 9133 & 2.2 & 43 & MR \\
\hline 29. & DKC 8101 & 3.6 & 71 & $\mathbf{S}$ \\
\hline 30. & KMH super 244 & 3.8 & 76 & $\mathbf{S}$ \\
\hline 31. & KMH 25K45 & 4.3 & 86 & HS \\
\hline 32. & КМH 3110 & 2.4 & 47 & MR \\
\hline 33. & Pioneer 30 V 92 & 4.1 & 81 & HS \\
\hline \multirow[t]{3}{*}{34.} & Pioneer 3396 & 4.5 & 89 & HS \\
\hline & Sem & 0.09 & & \\
\hline & CD & 0.28 & & \\
\hline
\end{tabular}

1- Resistant (R); 1.1-2.5 Moderately resistant (M R) 2.6-3.5- Susceptible (S), 3.6-5.0 -Highly Susceptible (H S) 


\section{Plate.1.Petridish method of screening}

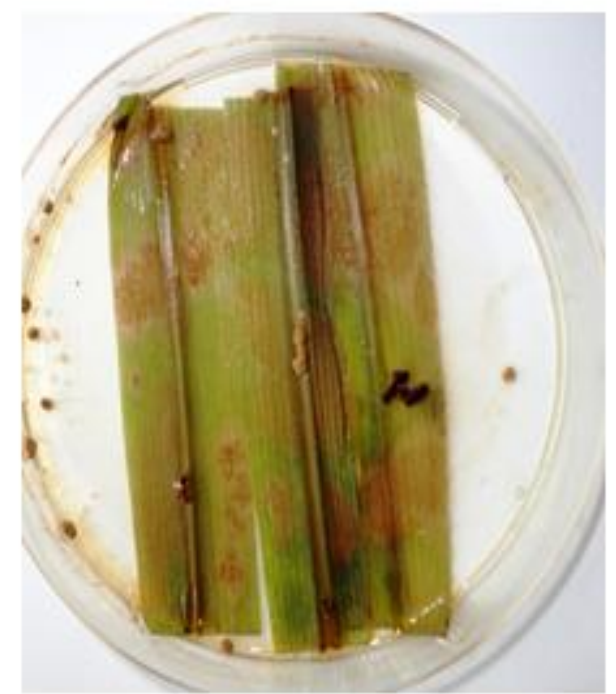

Plate 2. BLSB symptoms on maize cob

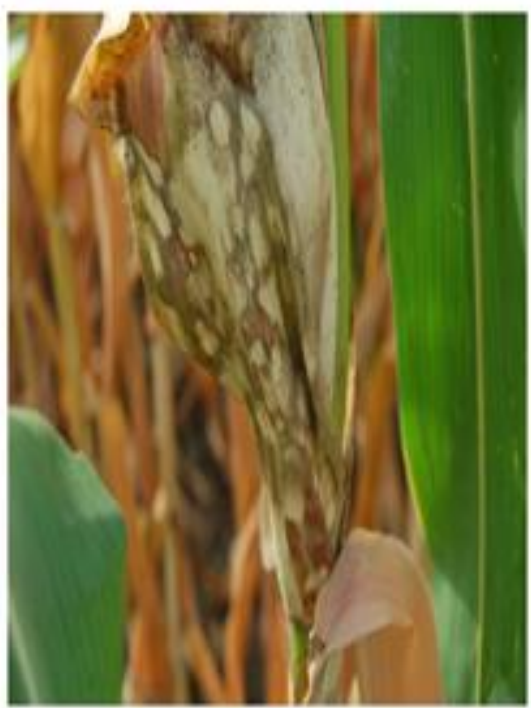




\section{Plate 3. Caking of the cob with sclerotia}

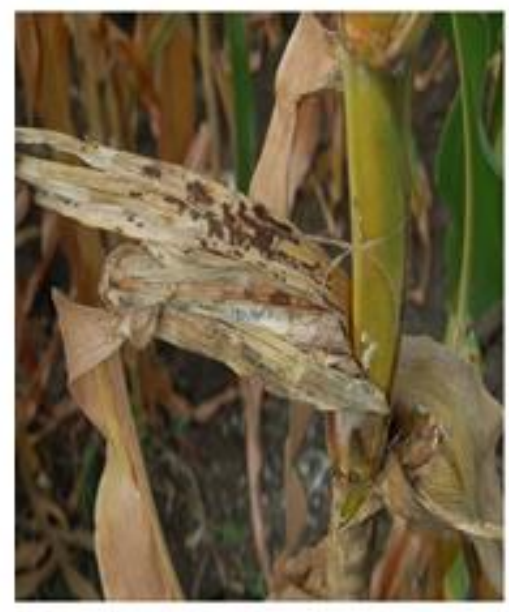

Screening under lab conditions

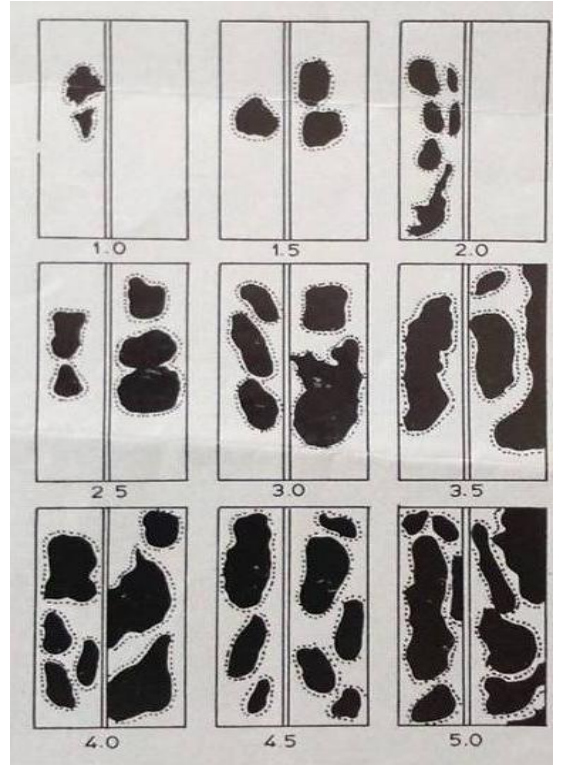

Disease Score Reaction

\begin{tabular}{|l|l|}
\hline 1 & Resistant (R) \\
\hline $\mathbf{1 . 1}-\mathbf{2 . 5}$ & Moderately resistant (M R) \\
\hline $\mathbf{2 . 6 - 3 . 5}$ & Susceptible (S) \\
\hline $\mathbf{3 . 6 - 5 . 0}$ & Highly Susceptible (H S) \\
\hline
\end{tabular}


The genotypes most severely infected generally had severe symptoms on the lower leaves, but more importantly, they had the most rapid development of systemic infection on the upper leaves, including the husk (Plate $2 \& 3)$

The per cent disease index calculated thirty days after inoculation in field trial revealed that PFSR-1 recorded highest PDI 97 with the average disease score 4.9. All the inbred lines and the hybrids showed variation with regard to Percent Disease Index and ranged from 2097 PDI. Out of the 12 hybrids screened for disease resistance, it was found that DHM117 was resistant and the remaining all hybrids were more or less affected by the disease. However, the hybrids DKC 9145, DKC 9133 and KMH 3110 were found moderately resistant with disease scores 2.7 , 2.4 and 2.4 respectively.

In case of inbred lines, PFSR-9-2 had shown resistant reaction with PDI 20 whereas the PFSR-6-1 and PFSR6-2 were found moderately resistant with PDI 45 and 46 respectively. Among 22 inbred lines 10 lines had shown highly susceptible reaction whereas 8 were found to be susceptible to BLSB. The laboratory and field evaluation data corresponded in actual disease rating as well as in terms of categorization in to resistant, MR, S and HS.

Germplasm evaluation was extensively carried out in the past using a large number of maize varieties, hybrids and inbred lines to find our resistance source to BLSB but the success in achieving the absolute resistance seems to be impracticable. At present narrow genetic base for resistance to BLSB has been found to be a bottleneck for an effective resistance breeding programme. However, the lines reported in this study as promising can be utilized as such or their resistance can be transferred into commercial varieties using cyclic breeding scheme to meet the immediate challenges posed by BLSB.

The observations on differential responses of the maize lines to BLSB disease are in congruence with observations from different researchers.Among the 29 inbreeds of maize analyzed, only a single genotype CA00106,recorded moderate resistance to BLSB at all the three locations and the remaining were found highly susceptible (Anshu et al., 2007). The pooled data of three years $(2003-2005)$ revealed that the genotypes, DRLT-180 IC324207, G-RS-7, RKU-193 IC309233and MZ-80 IC339731 of National Bureau of Plant Genetic Resource Station, Shillong were resistant (with disease rating 10. to 2.0), while, RS-9 and RKU-113 IC309153 were susceptible (4.1 to 5.0) and the rest others were intermediate (2.1 to 4.0) in disease reaction of BLSB (Biswas et al., 2007).

Maize inbred lines, CA003134, CA00396 and CA00310 (CML 465) showing intermediate reaction were also found to have higher degree of tolerance against BLSB than other lines. Similarly, it has also been found that inbred lines CA14510 (CML 428), CA14524 (CML 474) and Suwan 1 (S) C\# f-f possessed high degree of tolerance to BLSB (Sharma et al., 2005).

The laboratory method used was proved useful for screening of maize germplasm to BLSB. It can be helpful in rapid identification and elimination of susceptible to highly susceptible cultivars. In addition the use of excised leaf pieces allows precise control of incubation, temperature and humidity conditions. This method is also advantageous because of ease in operation, handling and observation. Moreover it requires lesser amount of test material. The method was successfully used to study host range (Ahuja, 1976) and relationship of temperature and 
relative humidity with the development of BLSB (Ahuja and Payak, 1981)

\section{Acknowledgements}

We thank AICRP Maize centre, Rajendranagar, PJTSAU, Hyderabad for providing the seed material of the inbred lines and hybrid used in this study. Our thanks are Associate Director of Research, RARS, Lam, Guntur, Andhra Pradesh for their kind support in field experimentation. The study was undertaken as a part of the doctoral research of the first author.

\section{References}

Ahuja, S.C. (1976). Investigations on banded leaf \& sheath blight of maize. Ph.D. Thesis, IARI, New Delhi.

Ahuja, S.C. and Payak, M.M. (1978). A field inoculation technique for evaluating maize germ plasm to banded leaf and sheath blight. Indian Phytopath. 31: 517-520.

Ahuja, S.C. and Payak, M.M. (1981). Relationship of relative humidity and temperature levels with the development of banded leaf and sheath blight of maize. Zeits. fur Pflanzen. und Pflanzenschutz,88: 265-268.

Ahuja, S.C. and Payak, M.M. (1983). A rating scale for banded leaf and sheath blight of maize. Indian Phytopath. 36: 338340 .

Anshu Garg, B.M., Prasannn, R.C., Sharmn, R.S., Rathore, S.C., Saxena and S.V.S. Chauhan. (2007). Identification of resistance sources to banded leaf and sheath blight (Rhizoctonia solani f. sp. sasakil) in maize. Indian Phytopath. 60 (2): 162-166

Huang, M.B., Tang. J, Yang, J.P. and Yang, K.C. (2007). Research advance on Banded Leaf and Sheath Blight of maize. Southwest China J. Agric. Sci. 20(2):209-21.

Jiang, H.L., Ding, X. and Ma, H. (1991). The occurrence and chemical control of maize sheath blight (Rhizoctonia solani) in Rugao of Jiangsu. PlantProtection 6: 11-12.

Lal, S., Baruah, P. and Butchaiah, K. (1980). Assessment of yield losses in maize cultivars due to banded sclerotial disease. Indian Phytopath. 33: 440-443.

Payak, M.M. (1955). A modified petri dish method for rust infection on excised leaves. Experientia 21:239-241

Payak, M.M. and Sharma, R.C. (1985). Maize diseases and approaches to their management in India. Trop. Pest Mgmt. 31: 302-310.

Puzari, K.C., Saikia, U.N., Bhattacharyya, A. and Bhattacharyya, A. (1998). Management of banded leaf and sheath blight of maize with chemicals. Indian Phytopath. 51: 78-80.

Sharma, G. and Saxena, S.C. (2002). Integrated management of banded leaf and sheath blight of maize (Zea mays L.) caused by Rhizoctonia solani Kuhn. Adv. Plant Sci. 15: 107-113.

Sharma, R.C. and Hembram, D. (1990). Leaf stripping - a new method to control banded leaf and sheath blight of maize. Curr Sci. 59: 745-746.

Sharma, R.C. and Rai, S.N. (1998). Chemical control of banded leaf and sheath blight of maize. Indian Phytopath. 52: 94-95.

Sharma, R.C., De Leon, C. and Singh, N.N. (2000). Banded leaf and sheath blight of maize - Its importance and current breeding efforts. In: Proc. $T^{\prime \prime}$ Asian Regional Maize Workshop, PCARRD, Los Banos, Philippines (Eds. Vasal, S.K., Gonzalez-Ceniceros, F. and XingMing, F.), CIMMYT, Mexico, pp. 284289.

Sharma, R.C., Rai, S.N. and Batsa, B.K. (2005). Identifying resistance to banded 
leaf and sheath blight of maize. Indian Phytopath. 58: 121-122.

Subrata Biswas, K. Chattopadhyay and Singh, N.P. 2007. Evaluation against sheath blight disease of maize under natural conditions Indian Phytopath. 60 (3): 302-305

Wang, X.M. and Dai, F.C. (2001). The Field Manual of Plant Diseases and Insect Pests of Maize. Press of Agricultural Science and Technology, China, pp. 92.

\section{How to cite this article:}

Bindu Madhavi, G., L.N. Hanuman, G. Uma Devi, K. Vijay Krishna Kumar, T. Ramesh Babu and Naidu, T.C.M. 2018. Screening of Maize Inbred Lines and Popularly Grown Hybrids against Banded Leaf and Sheath Blight Disease Incited by Rhizoctonia solani f. sp. sasakii Exner. Int.J.Curr.Microbiol.App.Sci. 7(11): 883-892.

doi: https://doi.org/10.20546/ijcmas.2018.711.105 